\title{
Tratamento da endocardite bacteriana causada pelo uso de prótese valvar e cateteres: uma revisão bibliográfica
}

\author{
Treatment of bacterial endocarditis caused by the use of valve prosthesis and catheters: a \\ bibliographic review
}

Tratamiento de endocarditis bacteriana causada por el uso de prótesis de válvula y catéteres: una revisión bibliográfica

Jade Menezes Maia ${ }^{1 *}$, Karine Gomes Bandeira Desteffani ${ }^{1}$, Mara Iza Alves Silva ${ }^{1}$, Letícia Karen Rodrigues de Souza ${ }^{1}$, Andressa Schmidt do Nascimento ${ }^{1}$, Angelo Antonio Leão Oliveira ${ }^{1}$, Marcia Cristina Monteiro Guimarães ${ }^{1}$.

\section{RESUMO}

Objetivo: O presente trabalho tem como objetivo a realização de uma revisão bibliográfica em relação aos possíveis tratamentos da endocardite bacteriana, causada pelo uso de prótese valvar e cateteres, e seus principais agentes etiológicos. Revisão Bibliográfica: A endocardite bacteriana (EB) ocorre pela inflamação do endocárdio, sendo frequente em indivíduos portadores de prótese valvares e cateteres vasculares. Estudos indicam que as principais bactérias encontradas na endocardite são: Staphylococcus aureus, Streptococcus viridans, Streptococcus epidermis e Enterococcus e Gram negativos. Os tratamentos mais utilizados são feitos a partir do uso de penicilina, associada ou não a aminoglicosídeos e vancomicina no caso de bactérias resistentes à penicilina. Considerações finais: A partir dos estudos analisados é possível inferir que a EB está associada a morbidade e mortalidade significativas e por isso, é importante identificar os fatores determinantes para o desenvolvimento da doença, como indivíduos que utilizam prótese valvar e cateteres. Além disso, percebe-se que de acordo com o agente etiológico identificado a partir de exames específicos, é possível elaborar estratégias eficazes de tratamento e controle da doença.

Palavras-chave: Endocardite, Tratamento, Prótese.

\begin{abstract}
Objective: The present study aims to carry out a bibliographic review in relation to the possible treatments for bacterial endocarditis, caused by the use of valve prostheses and catheters, and their main etiological agents. Bibliographic Review: Bacterial endocarditis (BE) runs due to inflammation of the endocardium, being frequent in individuals with valve prostheses and vascular catheters. Studies indicate that the main bacteria found in endocarditis are: Staphylococcus aureus, Streptococcus viridans, Streptococcus epidermis and Enterococcuse gram negative. The most used treatments are made from the use of penicillin, associated or not with aminoglycosides and vancomycin in the case of bacteria resistant to penicillin. Final considerations: From the studies analyzed, it is possible to infer that BE is associated with significant morbidity and mortality and, therefore, it is important to identify the determining factors for the development of the disease, such as individuals using valve prostheses and catheters. In addition, it is clear that according to the etiological agent identified from specific tests, it is possible to develop effective strategies for treatment and control of the disease.
\end{abstract}

Keywords: Endocarditis, Treatment, Prosthesis.

\footnotetext{
${ }^{1}$ Centro Universitário Metropolitano da Amazônia (UNIFAMAZ), Belém - PA.

*E-mail: jademmaia23@gmail.com
}

SUBMETIDO EM: $8 / 2020$

| ACEITO EM: 9/2020

PUBLICADO EM: 11/2020 


\section{RESUMEN}

Objetivo: El presente estudio tiene como objetivo llevar a cabo una revisión bibliográfica en relación con los posibles tratamientos para la endocarditis bacteriana, causada por el uso de prótesis valvulares y catéteres, y sus principales agentes etiológicos. Revisión bibliográfica: La endocarditis bacteriana (EB) se produce debido a la inflamación del endocardio, siendo frecuente en individuos con válvulas protésicas y catéteres vasculares. Los estudios indican que las principales bacterias encontradas en la endocarditis son: Staphylococcus aureus, Streptococcus viridans, Streptococcus epidermis y Enterococcuse gram negativos. Los tratamientos más utilizados están hechos del uso de penicilina, asociada o no con aminoglucósidos y vancomicina en el caso de bacterias resistentes a la penicilina. Consideraciones finales: A partir de los estudios analizados, es posible inferir que la EB está asociada con una morbilidad y mortalidad significativas $y$, por lo tanto, es importante identificar los factores determinantes para el desarrollo de la enfermedad, como los individuos que usan prótesis valvulares y catéteres. Además, está claro que de acuerdo con el agente etiológico identificado a partir de pruebas específicas, es posible desarrollar estrategias efectivas para el tratamiento y control de la enfermedad.

Palabras clave: Endocarditis, Tratamiento, Prótesis.

\section{INTRODUÇÃO}

A endocardite bacteriana (EB) é a inflamação da camada interna das câmaras cardíacas e válvulas cardíacas (endocárdio), que pode levar a obstrução ou insuficiência valvar, abscesso miocárdico ou aneurisma micótico. Além disso, a infecção pode provocar febre, sopros cardíacos, petéquias, anemia e fenômenos embólicos.

Apesar dos avanços no tratamento, a endocardite infecciosa (EI) está associada à morbidade e mortalidade significativas e estão cada vez mais relacionada a portadores de prótese valvares e cateteres vasculares (JUNIOR FP, et al., 2020; COELHO AP, et al., 2018; MELO L, et al., 2017; PEREIRA CAZ, 2003; SOBREIRO DL, et al., 2019).

A El era mais frequente em jovens e adultos de meia idade com doença cardíaca reumática ou cardiopatias congênitas. Contudo, estudos recentes, mostram redução na incidência da El nestes grupos, principalmente em países desenvolvidos. Essa patologia está cada vez mais relacionada a portadores de prótese valvares, cateteres vasculares, dispositivos eletrônicos implantáveis, como marcapasso e cardiodesfribiladores e novos dispositivos cirúrgicos, como endoprotéses valvares implantadas por cateter (PEREIRA CAZ, 2003; COELHO AP, et al., 2018).

Porém, têm casos de doentes sem história de patologia valvular, o que levou à identificação de novos fatores de risco, como a degeneração valvular relacionada com a idade, hemodiálise, uso de drogas endovenosas e outras comorbidades, como a imunossupressão e a diabetes mellitus. Modernamente, a prevalência da endocardite infecciosa em doentes sem os fatores de risco clássicos aproxima-se dos $50 \%$. E a incidência da doença envolve o risco cumulativo destes fatores e isso contribui para que o número de casos aumente a partir 65 anos (NAIK RJ, et al., 2015).

Essa doença ainda possui grande letalidade apesar do avanço da antibioticoterapia e das técnicas cirúrgicas. Na maioria das vezes o mecanismo patogênico se expressa pela grande turbulência de fluxo sanguíneo que acaba provocando lesões endoteliais; ocasionando, assim, a formação de um trombo estéril que pode ser colonizado por bactérias (COELHO AP, et al., 2018).

Assim, o desenvolvimento da El requer a ocorrência simultânea de vários fatores independentes como alteração da superfície da válvula cardíaca para produzir um local adequado para fixação bacteriana e colonização; bacteremia com um organismo capaz de fixar e colonizar de tecido valvar; e criação de vegetação pelo organismo em proliferação dentro de uma matriz protetora de moléculas séricas (por exemplo, fibrina) e plaquetas (HOLLAND TL, et al., 2016). 
É uma patologia com alta variedade etiológicas como: Staphylococcus aureus, Streptococcus viridans, Streptococcus epidermis, Enterococcus e Gram-negativo e o grupo HACEK (Haemophilus, Actinobacillus, Cardiobacterium, Eikenella e Kingella) sendo o Staphylococcus aureus o organismo com maior destaque em termos de causa. Esse mostra-se com alta capacidade de levar a uma forma agressiva da doença, geralmente em populações vulneráveis, idosos e pacientes transplantados (CAHILL TJ, et al., 2017).

Ferreira AS (2013); relata que o diagnóstico se baseia principalmente em dados clínicos e epidemiológicos, devendo ser confirmado por exames laboratoriais e depende de suspeita. Entretanto, Cahill TJ, et al., (2017); descreve que apesar do diagnóstico da El ser baseado na hemocultura e na presença de vegetação no ecocardiograma, até $30 \%$ dos casos atuais são classificados como "possíveis", devido a achados inconclusivos de imagem e cultura. Há algumas explicações para este fenômeno: maior prevalência de germes diferentes da família Streptococcu-Staphylococcus; uso de antibiótico, podendo causar falso-negativo nas culturas; presença de dispositivos intracardíacos, que podem apresentar naturalmente imagens de difícil distinção com vegetações (CAHILL TJ, et al., 2017).

A classificação da endocardite contribui para direcionar o tratamento empírico classificam-se: quanto ao tipo de válvula acometida, quanto a fatores predisponentes específicos, quanto à evolução da doença (aguda/subaguda), quanto ao local de aquisição da infecção, quanto ao agente etiológico. No exame laboratorial coleta-se hemogramas e hemoculturas que podem ser negativas ou positivas. Na suspeita pedese ecocardiograma e sugere-se a escolha do ecocardiograma transesofágico, que possui maior sensibilidade (PESTANA L, QUERIDO C, 2016).

O tratamento ocorre de maneira diferente na El tardias e na El precoce. Nas El tardias, quadros subagudos e pacientes com bom estado geral, o início do tratamento pode ser retardado por 24/48 horas, na tentativa de isolar o microrganismo responsável. Se não houver crescimento após 48 horas, o antibiótico deve ser iniciado baseado no quadro clínico e na possível porta de entrada pela história clínica, epidemiológica ou pelo exame físico. Já na El precoce, caracterizada por febre elevada, calafrios e hemograma infeccioso, deve-se iniciar os antibióticos imediatamente após a coleta das hemoculturas. (SILVA VQ, 2005; PESTANA L, QUERIDO C, 2016).

Apesar do desenvolvimento dos exames complementares que auxiliam o seu diagnóstico e das abordagens terapêuticas, a El mantém uma elevada morbimortalidade. Pacientes com endocardite envolvendo próteses podem evoluir com acometimento perivalvar, abcessos ou descontrole da doença, por isso, é necessário a avaliação cirúrgica com o objetivo de reduzir a mortalidade (FERREIRA AS, 2013).

A partir do exposto, percebe-se a importância de identificar os possíveis tratamentos para a EB. Diante disso, o presente trabalho tem como objetivo a realização de uma revisão bibliográfica em relação aos possíveis tratamentos da endocardite bacteriana, causada pelo uso de prótese valvar e cateteres, e o direcionamento desse tratamento de acordo com o agente etiológico identificado.

\section{REVISÃO BIBLIOGRÁFICA}

O coração normal é relativamente resistente à infecção. Assim, dois fatores são normalmente necessários para endocardite: uma anormalidade predisponente do endocárdio e microrganismos no fluxo sanguíneo (bacteremia). Raramente, a bacteremia maciça ou microrganismos especialmente virulentos provocam endocardite em valvas normais (COELHO AP, et al., 2018).

Galvão JLFM (2016); descreve que os microrganismos que infectam o endocárdio podem ser oriundos de locais infectados distantes (p. ex., abscesso cutâneo, gengivas inflamadas ou infectadas ou infecção das vias urinárias) ou ter portas de entrada óbvias, como acesso venoso central ou ponto de injeção de fármaco. Coelho AP, et al., (2018) e Sobreiro DL, et al., (2019) relatam que a lesão endotelial com aderência de microrganismos pode ser decorrente de procedimentos dentários, cateterismos, pacientes portadores de próteses valvares, alterações degenerativas valvares e uso de drogas por via intravenosa. 
O tratamento da EB requer uma equipe com formação e capacitação suficiente para otimizar os serviços de saúde e tomar decisões corretas, a fim de melhorar os resultados clínicos do paciente. É importante que a equipe seja composta por profissionais especializados, incluindo especialistas em doenças infecciosas, cardiologista e cirurgião cardíaco. Todos os pacientes devem receber terapia antimicrobiana, sendo o objetivo principal a eliminação da infecção. As várias características das vegetações cardíacas apresentam desafios particulares, incluindo alta densidade bacteriana, taxas lentas de crescimento bacteriano em biofilmes e baixa atividade metabólica de microrganismos. (HOLLAND TL, et al., 2016; CAHILL TJ, et al., 2017).

De acordo com Sobreiro DL, et al., (2019), Coelho AP, et al., (2018) e Melo L, et al., (2017) as bactérias mais prevalentes nas culturas de endocardite são: Staphylococcus aureus, Streptococcus viridans, Streptococcus epidermidis, Enterococcus e Gram negativos. Sendo que, Sobreiro DL, et al., (2019) expõem que a incidência de infecção endocárdica por estafilococos vem aumentando progressivamente, inclusive, predominando em relação aos estreptococos.

Burgos LM, et al., (2019); afirmam que, além das bactérias citadas por Sobreiro DL, et al., (2019), Coelho AP, et al., (2018) e Melo L, et al., (2017), a EB pode ser causada por qualquer um dos microrganismos do grupo chamado "HACEK" (sigla para Haemophilus spp., Aggregatibacter acti-nomycetemcomitans, Cardiobacterium hominis, Eikenella corrodens e Kingella spp.), sendo que, nas últimas décadas aumentaram os relatórios de endocardites causadas pelas bactérias desse grupo, sendo associados à serviços de saúde (por exemplo, uso de cateteres venosos centrais).

Melo L, et al., (2017); inferem que o tratamento das endocardites bacterianas está associado aos principais agentes etiológicos envolvidos. Após o diagnóstico clínico de endocardite bacteriana, as hemoculturas devem ser colhidas imediatamente e a antibioticoterapia deverá ser ajustada conforme o resultado da cultura e do antibiograma. O tratamento da El é classicamente realizado com antibióticos por via intravenosa (IV), porém em um trial atual foi observado que pacientes estáveis hemodinamicamente após 10 dias de antibioticoterapia IV, a transição para a terapia oral ambulatorial não foi inferior à continuação do tratamento com antibióticos IV em pacientes internados. Porém, este achado de apenas um estudo com metodologia e casuística limitada necessita de maiores evidências para validação de conduta (IVERSEN K, IHLEMANN N, GILL SU, et al., 2019).

De acordo com a ANVISA, no caso dos estreptococos, a penicilina cristalina ou ampicilina são as drogas de escolha, sendo indicado a associação com um aminoglicosídeo (gentamicina ou estreptomicina) para reduzir o tempo total de tratamento. No caso dos estafilococos a droga de escolha é a oxacilina associada ao uso de aminoglicosídeo. Em relação ao enterococos, o medicamento mais utilizado é a gentamicina com penicilina ou ampicilina. No caso das bactérias resistentes a penicilina, é utilizada vancomicina associada ou não a gentamicina.

Segundo Iversen K, et al., (2019); estudos in vitro comprovam que a adição de gentamicina à penicilina pode ser benéfica para o tratamento da endocardite por válvula protética causada por estreptococos suscetíveis à penicilina. Entretanto, como a gentamicina apresenta um elevado potencial de toxicidade, é clinicamente importante testar o nível de resistência à gentamicina antes de iniciar a terapia combinada.

No entanto, Cahill TJ, et al., (2017) não apoiam a utilização dos aminoglicosídeos afirmando que embora esses medicamentos tenham sido historicamente utilizados para $\mathrm{El}$, há dados crescentes para sugerir que 0 uso do mesmo possa estar causando danos sem benefício clínico, devido a frequência crescente de resistência causada, juntamente com o reconhecimento de dano potencial. Ademais, grandes estudos observacionais mostraram que a ampicilina / ceftriaxona é tão eficaz como ampicilina/gentamicina e ainda reduz os níveis de nefrotoxicidade.

De acordo com Iversen K, et al., (2019), a American Heart Association (AHA) e a Sociedade Europeia de Cardiologia (ESC) recomendam um regime de drogas triplas no tratamento para endocardite por válvula protética estafilocócica (com uma droga sendo a rifampicina). Essa recomendação é baseada em um estudo retrospectivo que descobriu que as válvulas dos pacientes que receberam terapia combinada tinham 5,9 vezes mais chances de serem negativas à cultura do que aquelas que receberam monoterapia. 
O segundo e o terceiro agentes do regime de drogas triplas devem ser gentamicina e rifampicina, se o organismo for suscetível a esses agentes. Se o organismo for resistente à gentamicina, deve-se procurar um aminoglicosídeo alternativo com base nas susceptibilidades aos antibióticos. Se o isolado for resistente a todos os aminoglicosídeos disponíveis, uma fluoroquinolona à qual a cepa é altamente suscetível pode ser usada.

Em relação ao grupo HACEK a droga de escolha são as cefalosporinas de terceira geração, pois a maioria desses organismos são resistentes a ampicilina devido a produção de beta-lactamase. Entretanto, se teste de sensibilidade in vitro confirmarem a suscetibilidade destes microrganismos a ampicilina, podendo esse medicamento ser utilizado (BADDOUR LM, WILSON WR, BAYER AS, et al., 2015).

Vale ressaltar que o tratamento da EB consiste em período prolongado de terapia antimicrobiana, sendo que, a duração da terapia deve ser suficiente para erradicar completamente os microrganismos nas vegetações cardíacas. Holland TL, et al., (2016) relatam que devido à baixa penetração de antibióticos nessas vegetações e às propriedades bactericidas lentamente de alguns dos medicamentos usados (como a vancomicina), geralmente são necessários ciclos prolongados de antibióticos.

Quando a atividade bactericida é rápida, cursos mais curtos podem ser possíveis. Por exemplo, a terapia combinada com penicilina ou ceftriaxona e um aminoglicosídeo é sinérgica para o El associado aos estreptococos do grupo viridans (VG) permitindo cursos eficazes em apenas duas semanas para cepas suscetíveis.

O tratamento da endocardite valvar nativa (NVIE) é menos complexo comparado ao tratamento da endocardite valvar protética (PVIE). Dessa forma, para endocardite infecciosa valvar nativa (NVIE), a duração do tratamento varia de 2 semanas a 6 semanas, enquanto uma duração de tratamento de seis semanas é geralmente usada para endocardite infecciosa valvar protética (PVIE). Os antibióticos para NVIE e PVIE são tipicamente os mesmos, com exceção do PVIE estafilocócico, para o qual é recomendada à adição de rifampicina e gentamicina (HOLLAND TL, et al., 2016). Quando a bactéria é multirresistente e as terapias medicamentosas e cirúrgicas foram esgotadas pode-se optar por transplante cardíaco, como uma medida de resgate e último recurso (COELHO AP, et al., 2018).

A terapêutica ocorre de acordo com agente infeccioso isolado e se é El por valva nativa ou proteica. No caso de valva protética utiliza-se Penicilina G cristalina por 6 semanas e gentamicina por 2 semanas. Já na valva nativa Streptococcus viridans e outros estreptococos com MIC para penicilina $0,1 \mathrm{~g} / \mathrm{ml}$ utiliza-se Penicilina G cristalina ou ceftriaxona por 4 semanas (HOLLAND TL, et al., 2016).

A distinção crítica na seleção de antibioticoterapia para $S$. aureus - a endocardite associada é resistente à meticilina (MRSA) ou é sensível à meticilina (MSSA). Antiestafilococos lactamâmicos são recomendados sempre que possível para a endocardite associado ao MSSA. Para a endocardite MRSA, à vancomicina tem sido historicamente o antibiótico de escolha e continua sendo uma terapia de primeira linha nas diretrizes de tratamento.

A daptomicina é aprovada pela FDA para o tratamento de adultos com S. aureus bacteremia e é uma alternativa à vancomicina para endocardite MRSA. A dose aprovada pelo FDA para o IE é de $6 \mathrm{mg}$ por $\mathrm{kg}$ por dia, mas utilizam-se doses mais altas (como 8 a $10 \mathrm{mg}$ por $\mathrm{kg}$ por dia) devido a preocupações com a resistência emergente ao tratamento (HOLLAND TL, et al., 2016).

Segundo Cahill TJ et al., (2017) antes da descoberta da penicilina, o EB era uma doença intratável. Santana RC (2015) explica que as penicilinas são as principais drogas de escolha utilizadas para o tratamento da endocardite e relata que a estrutura básica dessa droga é composta por um anel tiazolidínico ligado ao anel $\beta$-lactâmico e por uma cadeia lateral, sendo que, as diferenças no espectro de ação entre as penicilinas são causadas por modificações na cadeia lateral.

O mecanismo de ação das penicilinas é por meio da inibição da síntese da parede celular bacteriana, através do bloqueio da síntese da camada de peptideoglicano desta, interferindo na transpeptidação, tanto de bactérias gram-negativas quanto de gram-positivas. Ao inibir a síntese da parede celular, as penicilinas levam a bactéria a lise osmótica e morte (SANTANA RC, 2015; SILVA CC, 2018). 
De acordo com Silva CC (2018) e Miranda MCC (2014), as principais reações adversas clínicas de alergia a penicilina são o exantema maculopapular; erupção urticariforme; febre; broncoespasmo; vasculite; doença do soro dermatite esfoliante de Stevens Johnson e anafilaxia. Reações anafiláticas ocorrem em qualquer idade, com incidência de 0,004 a $0,04 \%$ em pacientes tratados com penicilinas, onde cerca de $0,001 \%$ morrem de anafilaxia, estima -se que a frequência de um choque anafilático é de $11 \%$ dos pacientes, ou seja, $1,2 \%$ da população mundial que faz uso de penicilinas.

Dentre o quadro de anafilaxia pode ocorrer uma hipotensão grave, com morte rápida, isso seria o quadro mais grave. Podem ocorrer outros episódios anafiláticos como broncoconstrição com asma grave, náuseas e vômito ou diarreia, dor abdominal, extrema fraqueza e queda de pressão e erupções cutâneas purpúricas.

No caso das bactérias resistentes a penicilina ou pacientes alérgicos à penicilina, a droga de escolha utilizada é a vancomicina. É um antibiótico glicopeptídeo tricíclico, indicado para o tratamento de infecções graves causadas por Staphylococcus aureus resistentes à meticilina, mas suscetíveis à vancomicina e indicada também para o tratamento de infecções causadas por outros microorganismos Gram-positivos suscetíveis à vancomicina; pacientes que não responderam a outras drogas, incluindo penicilinas e para o tratamento de infecções graves causadas por microorganismos suscetíveis à vancomicina e resistentes a outros antimicrobianos (BRUNIERA FR, et al., 2015; CAICEDO-OCHOA EY, et al., 2017).

De acordo com Terra M e Silva R (2017), à vancomicina tem efeito bactericida e o sítio-alvo do medicamento é a parede celular bacteriana que é constituída por peptideoglicano. A vancomicina atua na desestabilização da parede celular bacteriana, pois age ligando-se a porção terminal D- Ala-D-Ala de um pentapeptídeo encontrado em precursores de peptideoglicano, dificultando a etapa de transpeptidação, interferindo a forte ligação de D- Alanil-D-Alanina (D-Ala-DAla) e do pentapeptídeo, ocultando-o da transpeptidase que catalisa a síntese da ligação cruzada, interferindo na formação da parede celular, tornando a bactéria suscetível a sofrer lise.

A vancomicina está disponível principalmente para o uso parenteral, devendo ser administrado por via endovenosa. Não deve ser administrar por via intramuscular por causar dor, hipersensibilidade no local e até necrose (TERRA M, DA SILVA R, 2017).

Segundo Bruniera FR et al., (2015); na administração endovenosa, durante ou logo após a infusão rápida, os pacientes podem apresentar reações anafiláticas, incluindo hipotensão, dispneia, urticária ou prurido, choque e parada cardíaca. Além disso, a infusão rápida pode causar a síndrome do homem vermelho, devido a liberação de histamina, e é caracterizada por febre, síncope, taquicardia, hipotensão, prurido na pele, náusea ou vômito, erupção e vermelhidão na parte superior do corpo. Essas reações são comuns quando a administração é rápida (velocidade de infusão superior a $10 \mathrm{mg} /$ minuto) e geralmente desaparecem dentro de 20 minutos após término da infusão, mas podem persistir por várias horas.

Coelho AP et al., (2018); afirma que a endocardite infecciosa pode ter evolução subaguda e indolente ou mais aguda e fulminante, com potencial mais elevado de descompensação rápida. Sobreiro DL et al., (2019) relata que a endocardite bacteriana subaguda (EBS), geralmente tem início abrupto e progride rapidamente.

Geralmente, a EBS desenvolve-se em valvas anormais após bacteremia assintomática, decorrente de infecções periodontais, gastrointestinais ou geniturinárias. Já a endocardite em prótese valvar é mais comum após a troca valvar aórtica que a mitral, comprometendo igualmente as valvas mecânicas e biológicas. As infecções de início recente $(<2$ meses após a cirurgia) são provocadas principalmente por contaminação durante a cirurgia.

A endocardite bacteriana é uma condição relacionada à importante morbidade e altas taxas de letalidade. Silva VQ (2005) infere que pacientes submetidos a procedimentos médicos, cirúrgicos ou dentários que oferecem riscos para o desenvolvimento de $\mathrm{EB}$, devem ser submetidos à profilaxia adequada. Existem algumas condições em que a profilaxia é indicada e indispensável, como no caso de pacientes com próteses valvares (mecânicas, biológicas ou homoenxertos). 


\section{CONSIDERAÇÕES FINAIS}

Deste modo, é possível inferir que a endocardite infecciosa causada pelo uso de prótese e cateteres é uma inflamação da camada interna das câmaras cardíacas, comum em indivíduos idosos e hospitalizados. É causada principalmente por bactérias e dependendo do caso, são administradas medicações combinadas e específicas em relação à composição e ao tempo de uso. Este estudo serve para orientar o profissional de saúde na diferenciação dos tipos de antibioticoterapias direcionadas para cada tipo de microrganismo que incide nessa patologia, e aplicá-las de forma correta, visto que os antibióticos podem ter reações as quais podem piorar ainda mais o estado de saúde do paciente. Portanto, é necessário que seja feita uma avaliação entre os riscos e benefícios para cada paciente conforme cada diagnóstico.

\section{REFERÊNCIAS}

1. FERREIRA AS. Endocardite infecciosa - uma suspeita sempre presente. Rev Port Med Geral Fam 2013; 29:54-60.

2. GALVÃO JLFM. Endocardite infecciosa: Uma revisão do microrganismo ao tratamento.

3. GRINBERG M, SOLIMENE MC. Aspectos históricos da endocardite infecciosa. Ver. Assoc .Med .Bras 2011; 57(2):228-233

4. LAMAS CC. Endocardite infecciosa: Ainda uma doença Mortal. Arq. Bras. Cardiol. 2020; 114(1):9-11.

5. MIRANDA MCC. Reações adversas não alérgicas à suspensão injetável de benzilpenicilina benzatina. Ministério da Saúde. Fundação Oswaldo Cruz. Escola Nacional de Saúde Pública. 2014

6. PEREIRA CAZ. Achados clínico-laboratoriais de uma série de casos com endocardite infecciosa. J. Pediatr. (Rio J.) v.79 n.5 Porto Alegre set./out. 2003

7. SANTANA RC. Penicilinas. Curso básico de antimicrobianos. Divisão de MI-CM-FMRP-USP

8. SILVA CC. Reações alérgicas à penicilina. FUCAMP- Fundação Carmelitana Mário Plamério. Monte Carmelo, 2018.

9. SILVA VMFQS. Endocardite infecciosa. Manual de endocardite infeciosa. Disponível em: http://www.fmt.am.gov.br/manual/endocardite.htm

10. PESTANA L, QUERIDO C. Diretrizes para o Diagnóstico e tratamento de Endocardite Infecciosa. Serviço de Doenças Infecciosas e Parasitárias do Hospital Universitário Clementino Fraga Filho.

11. TERRA M, DA SILVA R. Vancomicina - um antimicrobiano de importância nosocomial. Brazilian Journal of Surgery and Clinical Research - BJSCR. 2017; 19(3): 76-80.

12. BADDOUR LM, et al. Infective Endocarditis in Adults: Diagnosis, Antimicrobial Therapy, and Management of Complications: A Scientific Statement for Healthcare Professionals From the American Heart Association. Circulation $2015 ; 132: 1435$.

13. BURGOS LM, et al. Endocarditis infecciosa por bacilos gram negativos no HACEK. Experiencia en un centro de alta complejidad de la República Argentina (1998-2016). Rev. argent. microbiol. vol.51 no.2 Ciudad Autónoma de Buenos Aires jun. 2019.

14. BRUNIERA FR, et al. The use of vancomycin with its therapeutic and adverse effects: a review. Eur Rev Med Pharmacol Sci, 2015; 19 (4): 694- 700.

15. CAHILL TJ, et al. Challenges in Infective Endocarditis. Journal of the American College of Cardiology, 2017; 69(3), 325-344. https://doi.org/10.1016/j.jacc.2016.10.066

16. CAICEDO-OCHOA EY, et al. Tratamiento de la bacteriemia por enterococo resistente a vancomicina con daptomicina versus linezolid: revisión sistemática y metanálisis. latreia. 2017; 30(1): 5-20.

17. COELHO AP, et al. Tratamento da endocardite infecciosa com troca valvar. Revista Caderno de Medicina 2018; 1(1).

18. FERREIRA AS. Endocardite infecciosa - uma suspeita sempre presente. Rev Port Med Geral Fam 2013; 29:54-60.

19. FRANCISCHETTO O, et al. Healthcare-associated infective endocarditis: a case series in a referral hospital from 2006 to 2011. Arquivos Brasileiros de Cardiologia. São Paulo, v. 103, n. 4, p. 292-298, 2014.

20. HOLLAND TL, et al. Infective endocarditis. Nat. Ver. Dis. Primers. 2016; 2:16059. Published 2016 Sep 1. doi:10.1038/nrdp.2016.59

21. IVERSEN K, IHLEMANN N, GILL SU, et al. Partial Oral versus Intravenous Antibiotic Treatment of Endocarditis. N Engl J Med 2019; 380:415.

22. JÚNIOR FP, et al. Análise de Escores de Risco para Predição de Mortalidade em Pacientes Submetidos à Cirurgia Cardíaca por Endocardite. Arq Bras Cardiol. 2020; 114(3):518-524.

23. MARTÍ-CARVAJA, AJ.et al. A comparison of different antibiotic regimens for the treatment of infective endocarditis (Review). Cochrane Database of Systematic Reviews 2020, Issue 5. Art. No.: CD009880.

24. MELO L, et al. Endocardite Infecciosa: Casuística do Departamento de Medicina Interna de um Hospital. Medicina Interna, Lisboa, 2017; 24(1): 19-23.

25. NAIK RJ, et al. Infective endocarditis prophylaxis: current practice trend among paediatric cardiologists: are we following the 2007 guidelines? Cardiology in the Young 2015: 1-7.

26. SOBREIRO DL, et al. Diagnóstico Precoce da Endocardite Infecciosa: Desafios para um Prognóstico Melhor. Arq Bras Cardiol. 2019; 112(2):201-203.

27. BRASIL. Portaria no 3.161, de 27 de dezembro de 2011. Dispõe sobre a administração da penicilina nas unidades de Atenção Básica à Saúde, no âmbito do Sistema Único de Saúde (SUS).

28. ANVISA. Agência Nacional de Vigilância Sanitária - Bulário eletrônico. Ministério da saúde. 